\title{
Attentional bias towards pain-related information diminishes the efficacy of
}

distraction: An experimental investigation.

Van Ryckeghem Dimitri M.L. ${ }^{1}$, Crombez Geert ${ }^{l}$, Van Hulle Lore ${ }^{1}$ \& Van Damme Stefaan $^{l}$

1 Department of Experimental-Clinical and Health Psychology, Ghent University, Henri Dunantlaan 2, B-9000 Ghent, Belgium, Belgium

Number of text pages: 32

Number of tables: 3

Number of figures: 0

* $\quad$ Corresponding author: Dimitri van Ryckeghem, Department of Experimental-Clinical and Health Psychology, Ghent University, Henri Dunantlaan 2, B-9000 Ghent, Belgium.

Tel: +32 926486 11, Fax: +329264 64 89, E-mail:

Dimitri.VanRyckeghem@ugent.be 


\section{Introduction}

The ability of attention to modulate pain processing $[32,51,57,66]$ makes it a key factor in how people cope with pain. Distraction, defined as directing attention away from pain, is probably one of the most intuitively and commonly used coping strategies [33]. Although distraction seems to be omnipresent in pain treatment programs for acute and chronic pain [20,41], results on its efficacy are variable. Some studies found that distraction reduces pain $[36,39,44,57,58,65]$, whereas other studies reported no effect $[25,35]$ or even counter-productive effects $[8,21]$. An understanding of the conditions under which distraction works is therefore required. Both pain-related factors (e.g., intensity, novelty, threat) and factors related to the task towards which attention is directed (e.g., task difficulty, motivational significance) are likely to play a role $[19,32,66]$.

A tendency to selectively attend to pain has been argued to hamper the efficacy of distraction $[15,32,72]$, and is largely discussed in the context of hypervigilance and attentional bias towards pain-related information [15,31]. Indeed, it is reasonable to assume that an attentional bias towards pain-related information may bring along difficulties to direct attention away from pain and, hence, result in a failure of distraction to diminish the experience of pain. However, there is no direct test of this idea. Most often, studies on attentional bias in pain aimed to validate the phenomenon (e.g. $[23,34,45,52])$, or attempted to identify its antecedent conditions (e.g. catastrophic thinking about pain, state/trait anxiety) $[4,46,47,62]$. In this study we focussed upon one of the putative consequences of attentional bias: To what extent does an attentional bias towards pain-related information hampers the efficacy of distraction? 
We address this question in an experimental environment, which allows optimal control over stimulus and other procedural parameters, and hence, may provide an in depth micro-analysis of attentional bias and its consequences. In a first phase, we assessed variables expected to be relevant in explaining attentional bias and distraction effects (i.e. state/ trait anxiety [34], catastrophic thinking about pain $[24,22,62]$, and self-reported pain of the experimental stimulus [electrocutaneous stimulus, ECS] [19]). In a second phase, we measured attentional bias towards cues that signal the possible occurrence of a painful ECS [62,67], and towards words that describe the sensory experience of the painful stimulus (ECS) (e.g. [71]) using well-established behavioural paradigms (respectively spatial cueing task $[62,63,64,67]$ and dot probe task $[4,26,30,52,54])$. In a third phase, we tested the efficacy of directing attention away from painful stimuli (ECS) to decrease pain experience (e.g. [69]).

We hypothesized that participants would show an attentional bias towards both cues signalling the experimental pain stimulus and words describing this pain stimulus. Furthermore, we expected that self-reported pain would be less when attention was directed away from pain than when it was directed towards pain. The crucial hypothesis of this study, however, was that a larger attentional bias would be associated with smaller effects of distraction. Finally, we wanted to explore whether an attentional bias towards pain-related information would mediate the relationship between catastrophic thinking about pain and the efficacy of distraction. 


\section{Method}

\section{Participants}

The sample consisted of 56 undergraduate students from Ghent University, who received course credits for participation (45 females; Mage $=18.1$ years, $S D=$ 1.1; 55 Caucasian) with normal or corrected-to-normal vision. Exclusion criteria included a self-reported current pain problem (e.g. fibromyalgia, back pain) or a self-reported current psychiatric problem (e.g., psychosis, anxiety disorder). Furthermore, all participants were required to have Dutch as a first language, because the experiment, including all instructions and stimulus materials, was undertaken in Dutch. Based on these criteria, two persons were excluded due to a headache on time of testing. One additional participant was excluded from the analyses due to outliers in the data on the distraction task $(<3 \mathrm{SD}$ above group mean). The final sample consisted of 53 undergraduate students (42 women; Mage $=18.1$ years, $S D=1.1 ; 52$ Caucasian). Experimental procedures were approved by the Ethics Committee of the Faculty of Psychology and Educational Sciences of the Ghent University, and written informed consent was obtained from all participants.

\section{Self-report measures}

Catastrophic thinking about pain was assessed with the Dutch version of the Pain Catastrophizing Scale (PCS) [12,56]. In this 13-item scale participants are asked to indicate the degree to which they experienced thoughts or feelings during pain episodes (e.g. "I become afraid that the pain will get worse"). This scale showed a good reliability and validity [60]. In the present study Cronbach's alpha of the total score was .88. Furthermore, a Dutch version of both the state and trait 
version of the State-Trait Anxiety Inventory (STAI) $[55,68]$ was administered to assess state and trait anxiety respectively. The questionnaire consists of 40 items in which people are asked to report their feelings in general (e.g. I feel happy) and at the moment (e.g. I feel upset). This questionnaire showed a good reliability and validity [68]. In the present study Cronbach's alpha of the STAI-S (STAI state version) and STAI-T (STAI trait version) were respectively .91 and .89. Pain experience was assessed by rating both pain intensity and pain unpleasantness of the ECS on an 11-point NRS (respectively range $0-10 ; 0=$ 'not at all intense'; $10=$

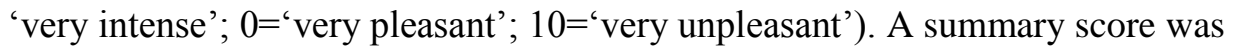
computed by averaging the pain intensity rating and the pain unpleasantness rating. (Cronbach's $\alpha=.93$ ).

Experimental tasks

All experimental tasks were programmed and presented by the INQUISIT Millisecond software package (Inquisit 2.06, 2008) on an Excel computer (Pentium 4, 2.8GHz, 512MB) with a $60-\mathrm{Hz}, 17$-inch colour CRT monitor. The viewing distance for all experimental tasks was approximately $60 \mathrm{~cm}$.

\section{$\underline{\text { Spatial cueing task }}$}

The spatial cueing task was adopted from previous research investigating attentional bias towards pain-related information (cues predictive of pain). This task has been repeatedly used in undergraduates with experimental pain $[62,63,64,67]$. For this task participants needed to detect a visual target (i.e. a small dot), which was preceded by coloured cues at the same (valid) or opposite (invalid) spatial location. Using classical conditioning one colour of the cue became a pain 
signal (CS+), because it was sometimes followed by a painful stimulus (i.e., an ECS). The other colour of the cue was never linked with an ECS (CS-). Overall, participants should be faster on valid than on invalid trials, a phenomenon called the cue validity effect. It is assumed that when participants' attention is biased towards pain-related cues, the cue validity-effect should be larger on CS+ trials than on CS- trials.

Stimuli. Target stimuli consisted of black squares $(1.1$ by $1.1 \mathrm{~cm})$, presented on a white background. Two coloured squares (pink and orange; $4.8 \mathrm{~cm}$ high $\times 6.5 \mathrm{~cm}$ wide) were used as spatial cues for the location of the targets.

Painful stimuli were ECS (bipolar; $3 \mathrm{~mA} ; 50 \mathrm{~Hz} ; 300 \mathrm{~ms}$; instantaneous rise and fall time), delivered by a constant current stimulator (DS5, Digitimer Ltd, Hertfordshire, UK). Stimuli were delivered by two lubricated Medcat surface electrodes $(1 \mathrm{~cm}$ diameter) at the distal radio-ulnar articulation on the wrist of the left arm.

Task course. Each trial began with a fixation cross in the middle of the screen (duration of $1000 \mathrm{~ms}$ ). Cues were presented 9.2 degrees from the fixation cross for a duration of $200 \mathrm{~ms}$. Target onset followed immediately after cue offset. On two third of the test trials, cue location correctly predicted target location (validly cued trials). On one third of the test trials, cue location incorrectly predicted target location (invalidly cued trials). Participants were instructed to respond to the left targets by pressing the ' 4 ' key with the index finger and to the right targets by pressing the ' 6 ' key with the ring finger of the right hand on a AZERTY computer keyboard. A trial ended when a participant responded or 2000 ms had elapsed. A 200-ms interval was given before the next trial was presented. In 
order to control for responses to cues instead of targets, a number of trials were presented, in which the cue was not followed by a target (catch trials).

Furthermore, in order to ensure that participants maintained gaze at the middle of the screen, a number of digit trials were presented. In these trials, the fixation cross was followed by a randomly selected digit between 1 and 9 for a duration of $100 \mathrm{~ms}$ (digit trials). Participants were instructed to type the number on the keyboard. Cues were presented in two colours. One colour was related to pain by a differential classical conditioning procedure. The conditioned cue (CS+) was on one third of the presentations followed by a painful stimulus (UCS). The other colour (CS-) was never followed by an UCS. Which colour was CS+ or CS- was counterbalanced across participants. The CS+ and CS- were presented equally often and in a random order.

The task started with a practice phase during which no pain stimuli were administered. This was followed by a test phase which consisted of 188 trials: 96 validly cued trials, 48 invalidly cued trials, 32 catch trials, and 12 digit trials. In order to facilitate the differential conditioning, the test phase started with two CS+ trials which were followed by an ECS.

\section{Dot-probe task}

The dot-probe task measures attentional bias towards pain words. This task was adapted from previous research $[29,30,52,54]$. For this task participants needed to detect a visual target (i.e. a small dot) as quickly as possible following the presentation of a word-pair. It is assumed that if participants' attention is biased towards the pain-related words, they should be faster at responding to the target 
when it appears at the location of the pain-related word ("congruent" trial) than at the location of the neutral word ("incongruent" trial).

Stimuli. The stimulus words were five Dutch words adopted from Crombez and colleagues (i.e. pricking, boring, flickering, electric and cutting). These words were found to be the best verbal descriptors for a painful ECS [11]. Control words were five Dutch words (i.e. follow, swarm, tread, backing, fit) matched for length and frequency in Dutch language using a computer program (Wordgen 1) that uses the CELEX and Lexique lexical databases for word selection [17]. In addition 10 neutral words, again matched for length and frequency in Dutch language using Wordgen 1, were used as stimulus words in the filler trials (i.e. import, open, precursor, hair, light, policy, foreland, deposit, discharge, steering). Stimulus words were presented in black uppercase letters in courier-new font with font size 37. Target stimuli consisted of black squares $(1.1$ by $1.1 \mathrm{~cm})$, presented on a white background.

Task course. Each trial started with the presentation of a fixation cross in the middle of the computer monitor $(500 \mathrm{~ms})$. This was followed by the presentation of a word pair, with one word appearing approximately 6.6 degrees above the location of the fixation point and the other appearing 6.6 degrees below. Each word pair remained on screen for $500 \mathrm{~ms}$ and subsequently a dot appeared in the place of one of the words. Using the keyboard, participants were asked to indicate as quickly as possible whether the dot had appeared in the upper ("4") or the lower ("6") location. The probe disappeared once a response was recorded or after 1500 ms. A 200-ms interval was given before the next trial was presented. 
Similarly as in the spatial cueing task also a number of catch and digit trials were presented.

For this task, participants completed a practice phase, followed by a test phase consisting of 186 randomly presented trials. During this phase each word was presented 9 times on the upper and lower position resulting in 90 experimental trials (42 pain congruent trials, 42 pain incongruent trials, 6 catch trials), 90 filler trials (of which 6 were catch trials) and 6 digit trials. Filler trials were included to reduce possible habituation to pain-related stimuli that might occur when all trials contained pain-related information $[38,40]$. Digit trials were presented in order to ensure that participants maintained gaze at the middle of the screen (see also spatial cueing task). Catch trials were presented to discourage participants from attending to only one side of the display and responding to mere presence or absence of the dot-probe (e.g. [2]).

Distraction task

The distraction task is a within subject paradigm that was adapted from previous research [69]. During this task participants were cued to direct their attention towards auditory targets (i.e. a tone) or towards somatosensory targets that could be painful (i.e. an ECS) or non-painful (i.e. a vibration). Depending on the cued modality (auditory/ somatosensory), participants needed to localize an auditory target or a somatosensory target. During each trial both an auditory stimulus and a somatosensory stimulus were present. It was expected that the painful stimuli would be rated as less painful when attention was directed towards the auditory targets (away from somatosensory stimuli), than when pain itself was the target. 
Stimuli. Painful stimuli were similar as in the spatial cueing task, but could be delivered at the wrist of both arms. Non-painful stimuli were delivered by a vibration element. This element consisted of a Nokia 3210 vibramotor, enveloped by a plastic cylinder $(1.3 \mathrm{~cm}$ in diameter and $3.0 \mathrm{~cm}$ long $)$, which was attached next to the electrode sites by means of velcro. Tactile stimuli were administered for 300 ms and had an instantaneous rise and fall time. Auditory stimuli were tones (440 Hz) presented through two loud-speakers (type, DELL A215) positioned approximately 35 degrees left and right from the middle. Auditory stimuli were presented for $300 \mathrm{~ms}$ and had an instantaneous rise and fall time.

Task course. In this task, participants were asked to localize either a somatosensory stimulus (electrocutaneous or vibrotactile) or an auditory stimulus. Somatosensory and auditory stimuli were simultaneously presented on each trial. In $50 \%$ of the trials participants were instructed to identify whether the tone was presented to the left or right location (distraction trials). On the remaining trials participants were instructed to identify whether the somatosensory stimulus was presented to the left or right location (focus trials). Each trial started with a visual cue consisting of a full coloured circle (either blue or yellow; $1000 \mathrm{~ms}$ duration) in the centre of the screen that indicated which modality was relevant (colour of the cue and the associated target modality were counterbalanced). Somatosensory and auditory stimuli were presented equally often at the same location and at the opposite location. Participants were instructed to localize (right/left) the stimulus of the cued modality as fast as possible by speaking aloud "right" or "left". Response latencies were recorded by a voice key (REACSYS R-51). Response errors were recorded by the experimenter on a trial to trial basis. 
The task started with a practice phase during which no pain stimuli were administered. This was followed by a test phase during which participants performed 128 trials. The trials were presented randomly. On 96 trials the somatosensory stimulus consisted of a non-painful vibrotactile stimulus. On 32 trials it consisted of a painful stimulus. Immediately after $25 \%$ of the trials with non-painful and $75 \%$ of the trials with painful stimuli, participants were asked to rate the intensity and the unpleasantness of the somatosensory stimuli. Ratings were electronically collected by means of two NRS scales presented on the screen. First pain intensity was assessed (range $0-10 ; 0=$ 'not at all intense; $10=$ 'very intense'), directly followed by the assessment of pain unpleasantness (range 0-10;

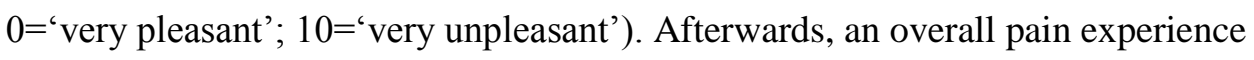
rating was computed for each condition by averaging the pain intensity and the pain unpleasantness ratings. Trials with vibrotactile stimuli were filler trials, and this for two reasons. First, inclusion of these trials reduced the overall percentage of trials that were followed by a rating. So, the possibility that participants had attended to the somatosensory stimuli during auditory modality trials because they expected to rate the somatosensory stimuli was kept low [18]. Second, filler trials reduced the potential effects of habituation on the perception of the painful stimulus [13].

\section{Procedure}

Upon arrival in the laboratory participants received the following information "We are interested in the influence of somatic stimuli on attention processes. Therefore you will have to perform three separate tasks. During the first and third task 
electrocutaneous stimuli will be administered. Most people find this kind of stimulation unpleasant" [61]. After having consented, participants first completed the questionnaires and were then familiarized with the ECS by administration of three stimuli of increasing intensity $(0.5 \mathrm{~mA}, 1,5 \mathrm{~mA}, 3 \mathrm{~mA})$. Participants rated the intensity and the unpleasantness of the $3 \mathrm{~mA}$ ECS (baseline pain experience). Next they were seated in front of a computer screen to complete the spatial cueing task. This was followed by a manipulation check. Participants rated the extent to which they expected that an ECS would be administered following each cue (CS+ or CS-) as well as their fear at the moment of seeing each cue on a 11-point numerical rating scale (anchored respectively $0=$ 'not at all' and $10=$ 'very strongly'; $0=$ 'not afraid' and $10=$ 'very afraid'). Next, participants performed the dot-probe task. This was followed by the distraction task.

\section{Data-analysis}

Statistical analyses were performed with SPSS statistical software, version 15.0 for Windows (SPSS Inc., Chicago, IL). Descriptive statistics, correlation analyses, ANOVAs and hierarchical linear regression analyses were performed to test the hypotheses two-tailed. All variables were normally distributed (all Kolmogorov-Smirnov $Z<1, p>$.10). Effect size-indices for dependent samples and the $95 \%$ Confidence Interval $(95 \% \mathrm{CI})$ were calculated $[6,10]$. For the hierarchical linear regression analyses, self-report measures were included as control variable if the significance level of the correlation with the distraction-index was less than .10 . 


\section{Results}

\section{Attentional biases indices}

\section{$\underline{\text { Spatial cueing task }}$}

Ratings indicated that the experimental manipulation was successful.

Participants reported more fear of the $\mathrm{CS}+$ cue $(M=4.26, S D=2.90)$ compared to the CS- cue $(M=0.91, S D=1.62), t(52)=8.71, p<.001, d=1.20 ; 95 \% \mathrm{CI}=0.84: 1.55$ and expected to receive an ECS after the CS+ cue $(M=6.26, S D=2.71)$ more often than after the CS- cue $(M=0.70, S D=1.54), t(52)=12.95, p<.001, d=1.78 ; 95 \% \mathrm{CI}=1.35$ : 2.21. Outlier handling was consistent with previous research $[62,63,64,67]$. Trials during which an ECS was applied were removed from further analyses. Also trials with errors and responses faster than $150 \mathrm{~ms}$ and slower than $750 \mathrm{~ms}$ were removed from further analyses $(<2 \%)$. Next, a 2 (Cue Validity: Valid vs Invalid) x 2 (Signal: CS- vs CS+) repeated measures ANOVA was performed. Results showed a main effect of Cue Validity $(F(1,52)=174.25, p<.001, d=1.81 ; 95 \% \mathrm{CI}=1.38: 2.25)$, indicating that participants were significantly faster on valid trials, than on invalid trials. No main effect of Signal was found $(F<1, d=0.04 ; 95 \% \mathrm{CI}=-0.23$ : 0.31). The expected interaction effect of Cue Validity and Signal was significant $(F(1,52)=12.49, p<.001, d=0.49 ; 95 \% \mathrm{CI}=0.20: 0.77)$, indicating a significant bias towards pain cues. An attentional bias index was calculated by subtracting the difference of invalid and valid CS- trials from the difference of invalid and valid CS+ trials (See Table 1 and 2).

\section{Dot-probe task}


Consistent with previous research $[26,28,52,54]$, trials with errors and responses faster than $200 \mathrm{~ms}$ and slower than $1000 \mathrm{~ms}$ were removed from further analyses $(<4 \%)$. To look whether participants had an attentional bias towards sensory pain words we compared participants' performance on incongruent trials with their performance on congruent trials by means of a paired sample $t$-test. Results indicated that participants did not show an attentional bias towards or away from pain-related information $(t(52)<1, d=0.04 ; 95 \% \mathrm{CI}=-0.23: 0.31)$. An attentional bias index was calculated by subtracting congruent trials from incongruent trials (See Table 1 and 2).

\section{TABLE 1}

\section{Efficacy of directing attention away from pain}

Analyses were performed on the ratings of the electrocutaneous stimuli only. Furthermore, trials with voice key errors and during which an incorrect response was given $(<6 \%)$ were removed from further analyses. The efficacy of distraction was examined by comparing the pain ratings on focus trials and distraction trials. A paired sample $t$-test indicated that participants rated the ECS as significantly less painful when attending to the auditory stimuli (distraction trials; $M=5.25, S D=2.23$ ) than when attending to the somatosensory stimuli (focus trials; $M=5.47, S D=2.17, t(52)=4.07, p<.001, d=0.56 ; 95 \% \mathrm{CI}=0.27: 0.85) . \mathrm{A}$ distraction-index was calculated by subtracting the pain ratings on distraction trials from the pain ratings on focus trials (See Table 2). 


\section{Correlation analyses}

Correlations between variables are shown in Table 2. Positive correlations were found between the three anxiety-related measures, i.e. STAI-S, STAI-T, PCS Furthermore, results indicated a positive correlation between baseline pain experience and the level of catastrophic thinking (PCS) and state anxiety (STAI-S). No relationship was found between the anxiety-related measures (STAI-S; STAI-T, PCS) and the attentional bias indices (spatial cueing task/ dot-probe task). Of particular importance were the correlations with the distraction-index. Results showed a significant negative correlation between attentional bias towards pain cues and the distraction-index, indicating that a larger attentional bias towards pain cues was related to a smaller effect of distraction. Also baseline pain experience correlated negatively with the distraction-index, indicating respectively that higher baseline pain experience was related to a smaller effect of distraction. No other variables correlated with the distraction-index.

\section{TABLE 2}

\section{Predictability of the efficacy of distraction}

Two hierarchical regression analyses were performed to investigate the additional value of each of the attentional bias indices in predicting the efficacy of distraction beyond the influence of other relevant variables. A first regression was performed with attentional bias towards pain cues (spatial cueing task) as independent variable and a second regression with attentional bias towards pain words (dot-probe task) as independent variable. In both analyses, we entered self- 
reported pain of the experimental pain stimulus at baseline. This was the only control variable that met our criterion $(p<.10)$. Results of the first regression analysis indicated a significant additional value of attentional bias towards pain cues in predicting distraction efficacy $\left(\Delta R^{2}=.09, p<.05\right)$. An independent significant contribution was found of (1) baseline pain experience $(\beta=-.27, p<$ $.05)$ and (2) attentional bias towards pain cues $(\beta=-.31, p<.05)$, indicating respectively that higher initial pain experience as well as a larger attentional bias towards pain cues relate to a smaller distraction-index. Results of the second regression analysis indicated no additional value of attentional bias towards pain words in predicting distraction efficacy $\left(\Delta R^{2}=.00, n s\right)$. (See table 3$)$.

\section{Mediation analyses}

No mediation analyses were performed to test whether an attentional bias towards pain-related information mediates the relationship between catastrophic thinking about pain and efficacy of distraction, because no initial correlation was found between catastrophic thinking and attentional bias towards pain-related information nor between catastrophic thinking and the efficacy of distraction.

\section{TABLE 3}

\section{Discussion}

This study investigated the effect of attentional bias towards pain-related information upon distraction efficacy. We also investigated the relationship between catastrophic thinking about pain, initial pain experience, state anxiety, trait 
anxiety, attentional bias towards pain-related information and the efficacy of distraction. Participants performed two attentional bias tasks, a spatial cueing task (cues predictive of pain) and a dot-probe task (sensory pain words), and, subsequently, a distraction task during which the efficacy of directing attention away from pain in diminishing pain was measured. Results can be readily summarised. First, participants displayed an attentional bias towards cues predictive for pain, but not towards pain-related words. Second, in line with previous research, participants perceived the pain stimulus as less painful when attending towards auditory stimuli than when attending towards pain stimuli $[36,39,44,57,58,65,69]$. Third, and of particular importance for this study, results indicated that the extent to which attention was biased towards signals of impending pain was negatively related to the efficacy of distraction. Attentional bias towards sensory words was not. Fourth, the reported intensity of the pain stimulus measured at baseline was negatively related to the efficacy of distraction. None of the other self-report variables (i.e. catastrophic thinking, state anxiety, trait anxiety) did affect attentional bias or distraction efficacy. Each of these findings is further discussed.

As expected, we found that a preferential processing of signals of pain was related to a reduced efficacy of a distraction technique. This finding supports the hypothesis that distraction from pain in people displaying an attentional bias towards pain-related information is far from optimal, because attention is shifted towards the pain-related information rather than towards the current goal, i.e. performing the distraction task $[15,66]$. Our results also indicate that distraction is less efficient for people who perceive the pain stimulus as more painful. This 
finding is in line with previous literature which indicated that a more intense pain stimulus draws more attention and interrupts persons more easily from an ongoing task $[19,51]$. The more easily pain interrupts the distraction task, the less efficient distraction will be. In contrast with our expectations, participants' level of catastrophic thinking, state anxiety and trait anxiety was not related to the efficacy of distraction or to the level of attentional bias towards pain-related information. This finding is in contrast with some previous studies that found a relationship between the anxiety-related measures and attentional bias indices [4,62, but see $5,43]$ and distraction efficacy $[22,24$, but see 9,65$]$. One possible explanation relates to the fact that catastrophic thinking and state anxiety were measured with general questionnaires, i.e. PCS, STAI-S. The lack of specificity of the self-report measures related to the experimental pain stimulus may have obscured the association with the efficacy of distraction and indices of attentional bias towards pain-related information as these were measured in an experimental setup with a specific experimental pain stimulus. Ajzen (1988) described this problem as a lack of compatibility between measurements [1]. He argued and demonstrated that a lack of compatibility between measurements may have a detrimental effect on the overall size of the association. A major disadvantage of the used self-report measures (STAI-S, PCS) is that the constructs are assessed without specification to a particular stimulus or context.

Furthermore, we did observe an attentional bias towards predictive pain cues, but not towards pain-related words. This finding might be explained by the stimulus material that was used in both tasks. It could be argued that cues which signal impending pain are more relevant for participants than words that describe 
the sensory characteristics of the pain stimulus (ECS). It may well be that pain words are not the best stimulus material to investigate attentional bias towards pain-related information $[16,46]$. Words are only semantic representations of pain and may be less capable in activating bodily threat than actual signals of pain $[14,66]$. In line with this argument is the finding that results of studies using pain words as stimulus material are inconsistent and effect-sizes are small [16,48,49], whereas results from studies that used cues which are predictive of pain as stimulus material are more consistent and show medium to large effect-sizes $[62,63,64,67]$.

This study may have some implications. First, the manipulation of attention to relieve pain should not be used as a "one size fits all" method in pain management. For individuals whose attention is biased towards pain-related information, simple distraction techniques may fail. It may then be important to increase the motivational relevance of these distraction techniques in order to overrule the attentional bias towards pain-related information $[3,50,70]$. Verhoeven and colleagues, for example, found that for people who catastrophize about pain, the performance of a distraction (i.e. a tone-detection) task only resulted in a reduction of pain during cold-pressor stimulation, when task engagement was increased with a motivational incentive (i.e. money) [70]. However, we may also consider other techniques such as exposure, which can be considered a clinical analogue of extinction, to decrease the attentional bias $[59,64]$. In line with this suggestion, Van Damme and colleagues (2004) found that the attentional bias that people show towards cues of impending pain largely disappears during an extinction phase [64]. 
Second, the growing literature on attentional bias towards pain-related information suggests that the prioritisation of attention towards pain-related information is a useful predictor of pain-related outcomes (see $[5,7,42]$, but see also $[29,30])$. Some consider such biases as etiopathological factors in the development, maintenance or exacerbation of pain problems $[53,54]$. In line with this view are the findings of an experimental study with healthy volunteers performing a cold-pressor task which showed that attentional retraining may affect peoples' pain threshold as well as their pain experience [37], indicating a causal influence of attentional bias towards pain-related information on pain outcomes. It remains yet unclear which pain outcomes (e.g. distress, pain, disability,...) may be expected to be affected by attentional retraining [53]. Specific theoretical models that guide research investigating the consequences of attentional bias (e.g. [15,72] are needed. Our study provides such a plausible rationale, and is one of the first to provide experimental data in support of that idea.

This study has some limitations. First, this study is one of the first of its kind, and it is performed in a well-controlled experimental environment with healthy students. One should however be cautious in generalizing its results to other settings, and other samples. Second, our sample may have been too homogenous in order to find correlations between the individual difference variables of pain catastrophizing, state and trait anxiety on the one hand and attentional bias on the other hand. Third, future research may opt to assess fear of pain instead of pain catastrophizing. Although highly interrelated, previous studies have found a relationship between fear of pain and attentional bias in healthy volunteers (e.g., [27]). Fourth, although our study is performed in a well-controlled 
environment, its design remains a predictive or longitudinal one. Therefore, one should be mindful of putative third variables that may account for the relationship between attentional bias towards pain-related information and distraction efficacy. As yet we were unable to identify such a variable. Pain catastrophizing had no effect upon attentional bias and distraction efficacy. Also, in our analyses we controlled for another putative third variable: the self-reported intensity of the pain stimulus, which was the same stimulus used in the spatial cueing paradigm and the distraction paradigm.

\section{Acknowledgements}

Preparation of this paper was partly supported by Grant BOF/GOA2006/001 of Ghent University and FWO project G.017807. There are no conflicts of interest that may arise as a result of this research. 


\section{References}

[1] Ajzen I. Attitudes, personality, and behaviour. Buckingham: Open University Press, 1988.

[2] Arndt, JE, Fujiwara, E. Attentional bias towards angry faces in traitreappraisal. Personality and Individual Differences 2012;52:61-66.

[3] Asmundson, GJG. Do attentional biases for pain depend on threat value of pain and competing motivation toward non-pain goals? Pain 2012;153:11401141.

[4] Asmundson GJG, Carleton, NR, Ekong J. Dot-probe evaluation of selective attentional processing of pain cues in patients with chronic headaches. Pain 2005; 114:250-256.

[5] Baum C, Huber C, Schneider R, Lautenbacher S. Prediction of experimental pain sensitivity by attention to pain-related stimuli in healthy individuals. Percept Mot Skills 2011;112:926-946.

[6] Borenstein M, Hedges LV, Higgins JPT, Rothstein HR. Introduction to Meta-analysis. West Sussex: Wiley, 2009. 
[7] Boston A, Sharpe L. The role of threat-expectancy in acute pain: effects on attentional bias, coping strategy effectiveness and response to pain. Pain 2005;119:168-175.

[8] Buckelew SP, Conway RC, Shutty MS, Lawrence JA, Grafing MR, Anderson SK, Hewett JE, Keefe FJ. Spontaneous coping strategies to manage acute pain and anxiety during electrodiagnostic studies. Arch Phys Med Rehabil 1992;73:594-598.

[9] Campbell CM, Witmer K, Simango M, Carteret A, Loggia ML, Campbell JN, Haythornthwaite JA, Edwards RR. Catastrophizing delays the analgesic effect of distraction. Pain 2010;149:202-207.

[10] Cohen J. Statistical power analysis for the behavioral sciences. San Diego, CA: McGraw-Hill, 1988.

[11] Crombez G, Eccleston C, Baeyens F, Eelen P. Attentional disruption is enhanced by the threat of pain. Behav Res Ther 1998;36:195-204.

[12] Crombez G, Eccleston C, Baeyens F, Eelen P. When somatic information threatens, catastrophic thinking enhances attentional interference. Pain $1998 ; 75: 187-198$ 
[13] Crombez G, Eccleston C, Baeyens F, Eelen P. Habituation and the interference of pain with task performance. Pain 1997;70:149-154.

[14] Crombez G, Hermans D, Adriaensen H. The emotional stroop task and chronic pain: what is threatening for chronic pain sufferers? Eur J Pain - Lond $2000 ; 4: 37-44$

[15] Crombez G, Van Damme S, Eccleston C. Hypervigilance to pain: an experimental and clinical analysis. Pain 2005;116:4-7.

[16] Dear BF, Sharpe L, Nicholas M, Refshuage K. Pain-related attentional biases: The importance of the personal relevance and ecological validity of stimuli. J Pain 2011;12:625-632.

[17] Duyck W, Desmet T, Verbeke L, Brysbaert M. Wordgen: A tool for word selection and non-word generation in Dutch, German, English and French. Behav Res Methods, Instrum Comput 2004;36:488-499.

[18] Eccleston C. The attentional control of pain: methodological and theoretical concerns. Pain 1995;63:3-10.

[19] Eccleston C, Crombez G. Pain demands attention: a cognitive-affective model on the interruptive function of pain. Psychol Bull 1999;125:356-366. 
[20] Elomaa MM, Williams ACC, Kalso EA. Attention management as a treatment for chronic pain. Eur J Pain 2009;13:1062-1067.

[21] Goubert L, Crombez G, Eccleston C, Devulder J. Distraction from chronic pain during a pain inducing activity is associated with a greater post-activity pain. Pain 2004;110:220-227.

[22] Goubert L, Crombez G, Van Damme S. The role of neuroticism, pain catastrophizing and pain-related fear in vigilance to pain: a structural equations approach. Pain 2004;107:234-241.

[23] Haggman SP, Sharpe LA, Nicholas MK, Refshauge KM. Attentional biases toward sensory pain words in acute and chronic pain patients. J Pain 2010;11:1136-1145.

[24] Heyneman N, Fremouw WJ, Gano D, Kirkland F, Heiden L. Individual differences and the effectiveness of different coping strategies for pain. Cognitive Ther Res 1990;14:63-77.

[25] Hodes RL, howland EW, lightfoot N, Cleeland CS. The effect of distraction on responses to cold pressor pain. Pain 1990; 41:109-114.

[26] Keogh E, Cochrane M. Anxiety sensitivity, cognitive biases, and the experience of pain. J Pain 2002;3:320-329. 
[27] Keogh E, Ellery D, Hunt C, Hannent I. Selective attentional bias for painrelated stimuli amongst pain fearful individuals. Pain 2001;91:91-100.

[28] Keogh E, Thompson T, Hannent I. Selective attentional bias, conscious awareness and the fear of pain. Pain 2003;104:85-91.

[29] Lautenbacher S, Huber C, Kunz M, Parthum A, Weber PG, Griessinger N, Sittl R. Pain hypervigilance as predictor of postoperative acute pain: Its predictive potency compared to experimental pain sensitivity, cortisol reactivity and affective state. Clin J Pain 2009;25:92-100.

[30] Lautenbacher S, Huber C, Schöfer D, Kunz M, Parthum A, Weber PG, Carbon R, Griessinger N, Sittl R. Attentional and emotional mechanisms related to pain as predictors of chronic postoperative pain: A comparison with other psychological and physiological predictors. Pain 2010;151:722-731.

[31] Leeuw M, Goossens MEJB, Linton SJ, Crombez G, Boersma K, Vlaeyen JWS. The fear-avoidance model of musculoskeletal pain: current state of scientific evidence. Behav Med 2007;30:77-94.

[32] Legrain V, Van Damme S, Eccleston C, Davis KD, Seminowicz DA, Crombez G. A neurocognitive model of attention to pain: Behavioral and neuroimaging evidence. Pain 2009;144:230-232. 
[33] Leventhal H. I know distraction works even though it doesn't! Health Psychol 1992;11:208-209.

[34] Liossi C, Schoth DE, Bradley BP, Mogg K. Time-course of attentional bias for pain-related cues in chronic daily headache sufferers. Eur J Pain 2009;13:963-969.

[35]McCaul KD, Monson N, Maki RH. Does distraction reduce pain-produced distress among college students? Health Psychol 1992;11:210-217.

[36] McCaul KD, Malott JM. Distraction and coping with pain. Psychol Bull 1984;95:516-533.

[37] McGowan N, Sharpe L, Refshauge K, Nicholas MK. The effect of attentional re-training and threat expectancy in response to acute pain. Pain 2009;142:101-107.

[38] Miller, MA, Fillmore, MT. The effect of image complexity on attentional bias towards alcohol-related images in adult drinkers. Addict;105:883-890.

[39] Miron D, Duncan GH, Bushnell MC. Effects of attention on the intensity and unpleasantness of thermal pain. Pain 1989;39:345-352. 
[40] Mogg K, Bradley BP, Miles F, Dixon R. Time course of attentional bias for threat scenes: testing the vigilance-avoidance hypothesis. Cog Emot 2004;18:689-700.

[41] Morley S, Shapiro DA, Biggs J. Developing a treatment manual for attention management in chronic pain. Cogn Behav Ther 2004;32:1-12.

[42] Munafò MR, Stevenson J. Selective processing of threat-related cues in day surgery patients and prediction of post-operative pain. Br J Health Psychol $2003 ; 8: 439-449$.

[43] Notebaert L, Crombez G, Van Damme S, De Houwer J, Theeuwes J. Signals of Threat Do Not Capture, but Prioritize, Attention: A Conditioning Approach. Emotion 2011;11,81-89.

[44]Petrovic P, Petersson KM, Ghatan PH, Stone-Elander S, Ingvar M. Painrelated cerebral activation is altered by a distracting cognitive task. Pain 2000;85:19-30.

[45] Pincus T, Fraser L, Pearce S. Do chronic pain patients 'Stroop' on pain stimuli? Brit J Clin Psychol 1998;37:49-58.

[46] Roelofs J, Peters ML, Fassaert T, Vlaeyen JWS: The role of fear of movement and injury in selective attentional processing in patients with 
chronic low back pain: A dotprobe evaluation. J Pain 2005;6:294-300.

[47] Roelofs J, Peters ML, van der Zijden M, Thielen FGJ, Vlaeyen JWS.

Selective attention and avoidance of pain-related stimuli: a dot-probe evaluation in a pain-free population. J Pain 2003;4:322-328.

[48] Roelofs J, Peters ML, Zeegers MPA, Vlaeyen JWS. The modified Stroop paradigm as a measure of selective attention towards pain-related stimuli among chronic pain patients: a meta-analysis. Eur J Pain 2002;6:273-286.

[49] Schoth DE, Nunez VD, Liossi C. Attentional bias towards pain-related information in chronic pain: a meta-analysis of visual probe investigations. Clin Psychol Rev 2011; in press

[50] Schrooten MGS, Van Damme S, Crombez G, Peters ML, Vogt J, Vlaeyen JWS. Nonpain goal pursuit inhibits attentional bias to pain. Pain 2012;153:1180-1186.

[51]Seminowicz DA, Davis KD. Interactions of pain intensity and cognitive load: the brain stays on task. Cereb Cortex 2007;17:1412-1422.

[52] Sharpe L, Dear BF, Schrieber L. Attentional biases in chronic pain associated with rheumatoid arthritis: hypervigilance or difficulties disengaging? J pain 2009;10:329-335. 
[53] Sharpe L, Ianiello M, Dear BF, Perry KN, Refshauge K, Nicholas MK. Is there a potential role for attention bias modification in pain patients? Results of 2 randomised, controlled trials. Pain 2012;153:722-731.

[54] Sharpe L, Nicholson PK, Rogers P, Dear BF, Nicholas MK, Refshauge K. A comparison of the effect of attention training and relaxation on responses to pain. Pain 2010;150:469-476.

[55]Spielberger, CD, Gorsuch RL, Lushene RE. Manual for the State-Trait Anxiety Inventory. Palo Alto, CA: Consulting Psychologists Press, 1970.

[56] Sullivan MJL, Bishop S, Pivik J. The pain catastrophizing scale:

Development and validation. Psychol Assess 1995;7:524-532.

[57] Tracey I, Ploghaus A, Gati JS, Clare S, Smith S, Menon RS, Matthews PM. Imaging attentional modulation of pain in the periaquaductal gray in humans. J Neurosci 2002;22:2748-2752.

[58] Valet M, Sprenger T, Boecker H, Willoch F, Rummeney E, Conrad B, Erhard P, Tolle TR. Distraction modulates connectivity of the cingulo-frontal cortex and the midbrain during pain - an fMRI-analysis. Pain 2004;103:399408. 
[59] Van Bockstaele, B., Verschuere, B., De Houwer, J., \& Crombez, G. (2010). On the costs and benefits of directing attention towards or away from threat-related stimuli: A classical conditioning experiment. Beh Res Ther 2012;48:692-697.

[60] Van Damme S, Crombez G, Bijttebier P, Goubert L, Van Houdenhove B. A confirmatory factor analysis of the Pain Catastrophizing Scale: invariant factor structure across clinical and non-clinical populations. Pain 2002;96:319324.

[61] Van Damme S, Crombez G, Eccleston C. Disengagement from pain: the role of catastrophic thinking about pain. Pain 2004;107:70-76.

[62] Van Damme S, Crombez G, Eccleston C. The anticipation of pain modulates spatial attention: evidence for pain-specificity in high pain catastrophizers. Pain 2004;111:392-399.

[63] Van Damme S, Crombez G, Eccleston C, Koster EHW. Hypervigilance to learned pain signals: a componential analysis. J Pain 2006;7:346-357.

[64] Van Damme S, Crombez G, Hermans D, Koster EHW, Eccleston C. The role of extinction and reinstatement in attentional bias to threat: A conditioning approach. Beh Res Ther 2006;44:1555-1563. 
[65] Van Damme S, Crombez G, Van Nieuwenborgh-De Wever K, Goubert G.

Is distraction less effective when pain is threatening? An experimental investigation with the cold pressor task. Eur J Pain 2008;12:60-67.

[66] Van Damme S, Legrain V, Vogt J, Crombez G. Keeping pain in mind: a motivational account of attention to pain. Neurosci Biobeh Rev 2010;34:204213.

[67] Van Damme S, Lorenz J, eccleston C, Koster E, De Clercq A, Crombez G. Fear-conditioned cues of impending pain facilitate attentional engagement. Clin Neurophysiol 2004;34:33-39.

[68] Van der Ploeg, HM, Defares PB, Spielberger CD. Handleiding bij de ZelfBeoordelings Vragenlijst, ZBV. Een Nederlandstalige bewerking van de Spielberger State-Trait Anxiety Inventory, STAT-DY., Lisse: Swets en Zeitlinger, 1980.

[69] Van Ryckeghem DML, Van Damme S, Crombez G, Eccleston C, Verhoeven K, Legrain V. The role of spatial attention in attentional control over pain: An experimental investigation. Exp Brain Res 2011;208:269-275.

[70] Verhoeven K, Crombez G, Eccleston C, Van Ryckegem D, Morley S, Van Damme $\mathrm{S}$. The role of motivation in distracting attention away from pain: an experimental study. Pain 2010;149:229-34. 
[71] Verkuil B, Brosschot JF, Thayer JF. A sensitive body or a sensitive mind? Associations among somatic sensitization, cognitive sensitization, health worry, and subjective health complaints. J Psychosom Res 2007;63:675-681.

[72] Vlaeyen JWS, Linton SJ. Fear-avaoidance and its consequences in chronic muscoskeletal pain: a state of the art. Pain 2000;85:317-332. 


\section{Tables}

Table 1

Means $(M)$ and Standard Deviations (SD) for Valid/Congruent Trials, Invalid/Incongruent Trials

\begin{tabular}{ccc}
\hline & $\begin{array}{c}\text { Valid/ congruent trials } \\
\text { M (SD) }\end{array}$ & $\begin{array}{c}\text { Invalid/ incongruent trials } \\
\text { M (SD) }\end{array}$ \\
\hline Spatial cueing task & $363.94(36.86)$ & $415.56(46.91)$ \\
CS+ & $369.00(35.85)$ & $409.06(41.76)$ \\
CS- & $415.71(46.69)$ & $416.39(47.31)$ \\
Dot - probe task & & \\
\hline
\end{tabular}


Table 2

Means $(M)$, Standard deviations $(S D)$ and Pearson correlation coefficients for all measures.

\begin{tabular}{lllllllll}
\hline & $M$ & $S D$ & 2 & 3 & 4 & 5 & 6 & 7. \\
\hline 1. Baseline pain experience & 6.10 & 1.87 & $.33^{*}$ & $.45^{* * *}$ & .20 & -.01 & -.01 & $-.26^{\mathrm{t}}$ \\
2. Pain catastrophizing & 17.43 & 8.09 & - & $.35^{*}$ & $.43^{* * *}$ & -.13 & -.20 & .19 \\
3. State anxiety & 38.68 & 8.04 & & - & $.47^{* * *}$ & -.16 & -.04 & -.04 \\
4. Trait anxiety & 38.83 & 7.74 & & - & .01 & -.03 & .20 \\
5. Attentional bias towards pain cues & 11.56 & 23.81 & & & - & .03 & $-.30^{*}$ \\
6.Attentional bias towards pain words & .69 & 19.06 & & & & - & -.06 \\
7. Distraction-index & .22 & .39 & & & & & & - \\
\hline
\end{tabular}


Table 3

Hierarchical regression analysis explaining distraction effectiveness. Standardized betas from the last step in the analyses are displayed.

\begin{tabular}{llllll}
\hline $\begin{array}{l}\text { Criterion } \\
\text { variable }\end{array}$ & Step & Predictor & Beta & $\Delta \mathrm{R}^{2}$ & Adj. $\mathrm{R}^{2}$ \\
\hline
\end{tabular}

Distraction-

index

$\begin{array}{lllll}1 & \begin{array}{l}\text { Baseline pain } \\ \text { experience }\end{array} & -.27^{*} & .07^{\mathrm{t}} & .05 \\ 2 & \begin{array}{l}\text { Attentional bias } \\ \text { towards pain cues }\end{array} & -.31^{*} & .09^{*} & .13\end{array}$

Distraction-

index

$\begin{array}{cllll}1 & \begin{array}{l}\text { Baseline pain } \\ \text { experience }\end{array} & -.26^{\mathrm{t}} & .07^{\mathrm{t}} & .05 \\ & \begin{array}{l}\text { Attentional bias } \\ \text { towards pain words }\end{array} & -.06 & .00 & .04 \\ { }^{\mathrm{t}}=p<.10, *=p<.05, * *= & p<.01 & & \end{array}$

